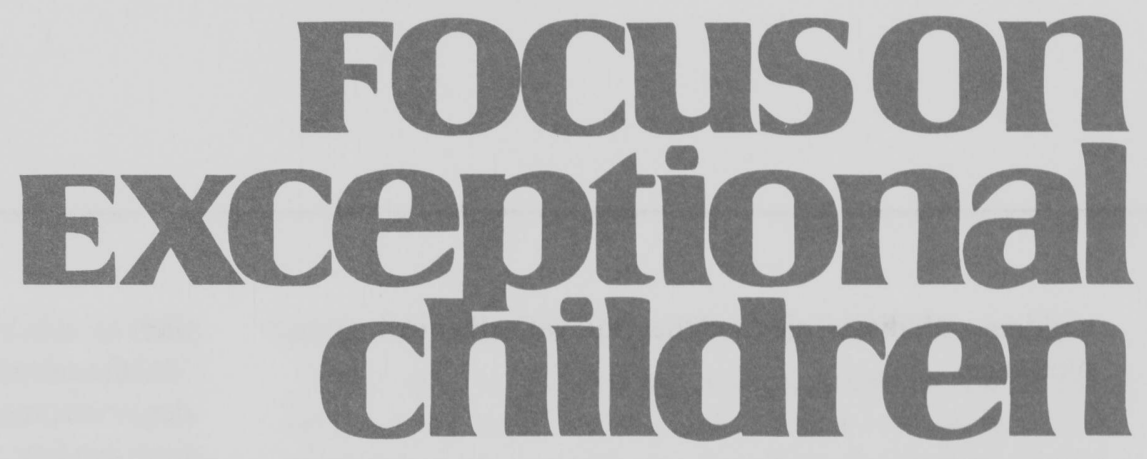

\title{
Developmentally Appropriate Practice: A Critical Analysis as Applied to Young Children with Disabilities
}

\section{Judith J. Carta}

In 1987 the National Association for the Education of Young Children (NAEYC) published guidelines for developmentally appropriate practice (DAP) to clarify types of activities the association deemed appropriate for children between birth and age 8 (Bredekamp, 1987). The document was constructed primarily in reaction to the "increasingly pervasive pressure for programs to conform to an academic model of instruction typical of programs designed for older children" (New \& Mallory, 1994, p. 1).

The NAEYC description of developmentally appropriate practice was organized around two major dimensions: the principle of age appropriateness ("that learning environments, teaching practices, and other program components should be planned based on what is generally to be expected of children of various ages and stages") (Bredekamp, 1993, p. 261) and the principle of individual appropriateness (that "adaptations should be made for the wide range of differences between individual children") (Bredekamp, 1993, p. 261). What was left unsaid but is still evolving is the manner in which these two principles come together to assist teachers in the organization and implementation of educational practices for young children with diverse abilities. For example, many people have interpreted the guidelines to mean that development in all children should be facilitated the same way: through certain conditions such as self-initiated and self-directed activity and through the teachers' provision of materials and activities that support children's play (Carta, Schwartz, Atwater, \& McConnell, 1991; Grossen, 1993; Lubeck, 1994). However, that is not the intent of the DAP guidelines. Unfortunately, although the DAP guidelines provide specific information regarding the age appropriateness principle detailing the types of materials and activities that are suitable for children of different ages, the guidelines are much less explicit in addressing how teachers should address the individually appropriate principle. As a consequence, teachers have been unclear about when to digress from age appropriate practices and how to modify teaching practices to address children's individual needs. This issue of how and when to individualize is of critical importance for teachers who are charged with educating young children with diverse needs.

This article discusses some of the basic premises and misconceptions that exist about developmentally appropriate practice and examines how the premises and practices of DAP diverge and overlap with recommended practices for teaching young children with disabilities. Specific instructional strategies that have proven to be effective for teaching young 
children with disabilities and that follow DAP guidelines are presented.

\section{ORIGINS OF DEVELOPMENTALLY APPROPRIATE PRACTICE}

The NAEYC published its DAP guidelines in 1987 in response to general concerns and specific issues regarding the manner in which young children were being served in early education programs. NAEYC had a general concern over the pervasive and growing emphasis on formal academic instruction in early childhood programs based on misconceptions about early development and learning (Bredekamp, 1987). Additionally, however, the organization had several specific concerns that drove their effort to define developmentally appropriate practice. First, although the NAEYC had used the term "developmentally appropriate" in its previously published early childhood accreditation criteria, it had never explicitly defined the term. As a consequence, the term was being translated into practice in widely different ways. For example: "Some people considered it developmentally appropriate for 4- and 5-year-olds to do an hour of seatwork, tod-

\section{Focuson
Exceptional
childiren}

ISSN 0015-511X FOCUS ON EXCEPTIONAL CHILDREN (USPS 203-360) is published monthly except June, July, and August as a service to teachers, special educators, curriculum specialists, administrators, and those concerned with the special education of exceptional children. This publication is annotated and indexed by the ERIC Clearinghouse on Handicapped and Gifted Children for publication in the monthly Current Index to Journals in Education (CIJE) and the quarterly index, Exceptional Children Education Resources (ECER). The full text of Focus on Exceptional Children is also available in the electronic versions of the Education Index. It is also available in microfilm from Xerox University Microfilms, Ann Arbor, MI. Subscription rates: Individual, \$30 per year; institutions, \$40 per year. Copyright (C) 1995, Love Publishing Company. All rights reserved. Reproduction in whole or part without written permission is prohibited. Printed in the United States of America. Second class postage is paid at Denver, Colorado. POSTMASTER: Send address changes to:

$$
\begin{aligned}
& \text { Love Publishing Company } \\
& \text { Executive and Editorial Office } \\
& 1777 \text { South Bellaire Street } \\
& \text { Denver, Colorado } 80222 \\
& \text { Telephone (303) } 757-2579
\end{aligned}
$$

Edward L. Meyen

University of Kansas
Glenn A. Vergason Georgia State University

Richard J. Whelan

University of Kansas Medical Center

Stanley F. Love

Publisher
Holly T. Rumpler

Senior Editor dlers to sit in high chairs with dittos, or babies in infant seats to 'do' the calendar" (Bredekamp, 1993, p. 261). Second, prekindergarten programs were being expanded in public school settings at a time when public schools were engaging in practices that did not seem consistent with sound early childhood practices. Examples of these public school practices included keeping children out of kindergarten after finding them "unready" based on screening test results and assigning them to a 2-year kindergarten track.

In response to these issues, the NAEYC organized a consensus-building process to define DAP not only to improve the quality of early childhood programs but also to provide a rallying point for early childhood educators attempting to establish political, advocacy, and professional goals (Johnson \& McChesney Johnson, 1992). The outcome of this consensusbuilding process was the 1987 publication Developmentally Appropriate Practice in Early Childhood Programs Serving Children From Birth Through Age 8 (Bredekamp, 1987), which defined DAP principles and provided examples of appropriate and inappropriate practices for different age-groups of children.

This set of guidelines was inspired by a constructivist approach to teaching and learning, strongly influenced by $\mathrm{Pi}$ aget and Vygotsky, that emphasized child-initiated learning and exploratory play activities (Bredekamp, 1993). The guidelines advised against using highly structured learning experiences for young children and using artificial motivation systems (e.g., high rates of teacher praise, tokens, or stickers). The assumption underlying these recommendations was that young children are intrinsically motivated to learn based on their desire to understand their environment. Furthermore, the guidelines warned that undue structure and artificial motivation systems could be detrimental to the self-esteem and emotional well-being of young children (Bredekamp, 1987; Elkind, 1987). Although the intent of the guidelines was to describe a continuum of teaching practices, many persons interpreted the guidelines as advocating one specific approach to teaching. Thus, many associated myths and misperceptions have emerged about DAP.

\section{MISPERCEPTIONS ABOUT DEVELOPMENTALLY APPROPRIATE PRACTICE}

A number of reasons have been offered for why so many myths have arisen about DAP. One idea is that misconceptions are inevitably associated with any complex motion that achieves popular attention (Bredekamp, 1993). A related idea is that misperceptions have arisen because many individuals have oversimplified the concept of DAP or tried to make this open-ended concept more finite and absolute (Kostelnik, 1992). Finally, although the guidelines were intended for all 
children, their lack of attention to children from diverse developmental levels and cultural backgrounds gave the guidelines the appearance of exclusivity and of being too narrowly conceptualized (Lubeck, 1994). Therefore, before one can determine the applicability of the DAP guidelines for children with disabilities, one must separate myth from reality.

\section{Myth \#1: Teachers Following a DAP Approach Should Never Use Direct Instructional Approaches}

This commonly held myth contends that in DAP-oriented classrooms, no structure exists and teachers never teach. Instead, all learning takes place in child-initiated exploration of the environment. Bredekamp (1993) clarified this myth by stating that DAP classrooms should be based on an interactive teaching paradigm. She asserted that teachers should employ a range of teaching behaviors "from nondirective (withholding attention, acknowledging) to directive (more intrusive) with the mediating behaviors of facilitating, supporting, and scaffolding in the middle. The point of such a continuum is that every one of these behaviors is appropriate on some occasions and exclusive use of any behavior renders it less effective" (p.267).

Bredekamp (1993) further clarified this issue by pointing out that some children require direct training and that teachers need to do more for them than provide a rich environment for nurturing social competence. "Inevitably, some children spend more time on a time-out chair or are neglected or rejected by their peers because they do not acquire the social problem-solving skills of other children. In such situations, the appropriate role of the teacher is to intervene" (p. 266). The reality about developmentally appropriate practice is that teachers should employ a continuum of teaching practices that vary in directiveness depending on individual children's and specific classroom needs.

\section{Myth \#2: Early Childhood Curriculum Should Be Based Entirely on Children's Interests and Should Not Be Goal-Directed}

This myth probably is based on overgeneralizing in reaction to programs that set inappropriate goals for children. For example, programs that set goals for children focused exclusively on rote academic skills such as memorizing number facts or tracing letters before the children have basic conceptual understanding of number representation or fine motor skills. The inappropriate practice exemplified here would be the particular choice of goals, not the goal-directed nature of the program. The reality of developmentally appropriate practice is that if programs are to be individually appropriate, teachers must assess children's needs, develop specific goals for individuals, and plan programs that address the unique goals and objectives of the children within the class.

\section{Myth \#3: Academics Have No Place in DAP Programs}

This myth is based on the contention that preschool children are not ready for academics. The misconception is in equating academics with rote instructional activities that are not meaningful to young children. In truth, academic concepts are wide ranging and can be interesting to preschool-aged children. The reality is that developmentally appropriate practice can incorporate academic activities that emphasize meaningful literacy and mathematical activities (Kostelnik, 1992).

\section{Myth \#4: DAP Applies Only to Children Who Are Typi- cally Developing, White, and Middle Class}

Many people have expressed misgivings about DAP's applicability to children from diverse backgrounds (e.g., Delpit, 1988; Jipson, 1991; Mallory, 1994). Some have questioned whether values expressed in the DAP guidelines concerning curriculum, interactions between adults and children, relations between home and school, and the assessment of children's development are universally accepted by individuals from different cultures (Jipson, 1991; Kessler, 1991; Walsh, 1991). Others have questioned the applicability of DAP for planning, carrying out, and evaluating early childhood programs that serve young children with disabilities (Carta, Schwartz, Atwater, \& McConnell, 1991; Kaminski \& Carey, 1993; Wolery, Strain, \& Bailey, 1992). They have contended that although DAP guidelines may support programs serving young children with special needs, the DAP principles do not go far enough in defining the practices that may be appropriate and necessary for serving these children. Leaders of NAEYC have concurred that the 1987 guidelines are inadequate for meeting the special needs of many young children (Bredekamp, 1993); however, more recent publications by NAEYC and collaborations between that organization and the Division for Early Childhood within the Council for Exceptional Children have made great strides in operationalizing how developmentally appropriate practice can be individualized for children with disabilities. The reality is that the concept of DAP is evolving, and recent publications have begun to clarify its applicability for children from diverse backgrounds and developmental levels (Bredekamp \& Rosegrant, 1992).

\section{Myth \#5: Programs Adhering to the DAP Guidelines Must Follow One Specific Approach If They Are to Be Implemented Correctly}

A common misunderstanding about the DAP guidelines is that they were meant to define a singular approach to teaching. The reality is that teaching approaches should vary depending on the children in the classroom and their diverse needs and experiences, the resources available, and the ex- 
pectations and values of the children's families and their communities (Kostelnik, 1992). Thus, there is no "one-sizefits-all" model of educational practice (Richarz, 1993). This concept is critically important in early childhood special education and must be emphasized in any translation of the DAP guidelines for young children with diverse abilities.

\section{Summary}

In summary, several misperceptions have surfaced regarding the principles of DAP. These myths have hindered the convergence of the fields of early childhood education (ECE) and early childhood special education (ECSE) at a time when educators have needed to find common ground concerning the education of young children with disabilities in inclusive settings. Unfortunately, an additional barrier exists in a parallel set of misperceptions about some of the strategies or practices advocated by the field of early childhood special education.

\section{MYTHS ABOUT RECOMMENDED PRACTICES IN ECSE}

Although the field of ECSE is relatively young, the ECSE practices recommended either by research or consensus among practitioners have changed dramatically over the past 25 years. In the past, ECSE was strongly influenced by the use of behavioral analysis strategies and direct instructional approaches, but more recently, the field has been evolving toward more naturalistic instructional approaches. The flux in the field has led to many misperceptions about ECSE practices. Among them are the following.

\section{Myth \#1: Most Children with Special Needs Must Be Taught in Very Structured Activities in One-to-One Settings With the Teacher}

Many people assume that individualization for children with special needs demands that they be taught individually. They conclude that ECSE teachers excessively structure their programs in their quest for individualization. This belief about ECSE was articulated by Johnson and McChesney Johnson: "In ECSE, one often finds teachers inadvertently stymieing young children with handicaps by being overbearing and providing an inordinate amount of structure and direction" (p. 450). This certainly is not recommended ECSE practice. Although the teacher must arrange the educational setting so that the child with special needs receives numerous opportunities to work on instructional objectives, these objectives can often be woven into typical classroom routines in which many children participate.

\section{Myth \#2: Activities That Follow Recommended Practices in ECSE Must Be Entirely Teacher-Directed}

A common myth is that young children with special needs are never allowed to follow their own interests or have fun in school. The typical misperception is that the entire day is spent in drill and practice on learning specific skills. Although young children with disabilities must be provided with ample opportunities to work on their individual goals and objectives, teachers can use many approaches to facilitate this instruction. Activities can be planned in which work on instructional objectives is directed by an adult, facilitated by a child's peers, or self-mediated by children engaging materials in the classroom environment. The reality of ECSE practice is that a multitude of classroom arrangements and continuum of structure are available for addressing children's instructional objectives.

\section{Myth \#3: In Typical ECSE Practice, Teachers Must Use Artificial Incentives to Get Children to Perform Behaviors}

Another misconception about ECSE is that teachers must use food, tokens, and other contrived rewards during instruction. In reality, recommended practice is for teachers to use the most natural consequences possible to motivate a child. Teachers must have available a wide range of reinforcers. For some children with very limited abilities, appropriate reinforcers may be edibles or special types of tactile stimulation. The goal in using these types of reinforcers is to help these children learn that specific behaviors, such as communicating, can have important consequences. But other children will be able to learn these behaviors without artificial incentives. For example, most children will learn communication skills simply as a result of obtaining the natural rewards that result from communication-desired or needed objects or events, attention or praise. Teachers of children with disabilities must become skilled at determining when natural rewards are effective and when other forms of reinforcement will initially be more efficient in teaching children new behaviors. An important ECSE practice in using artificial reinforcers is to move children in the direction of natural contingencies as soon as possible.

\section{Myth \#4: Curricular Content in ECSE Focuses on Academic Subskills or Individual Behaviors That Are Taught Out of Context}

ECSE curricular content often is depicted as inappropriate for preschoolers, nonfunctional, and not conceptually based. Goodman (1992), for example, described early childhood special education programs as "very intense instruction" in "preacademics." Similarly, Johnson and McChesney John- 
son (1992) described early childhood special education settings as "no-nonsense, back to basic academic programs that stress storage and retrieval of static knowledge" where instruction insists on "mastery to criteria" (p. 443). Such descriptions perpetuate the myth that young children with special needs must be or are typically taught discrete skills in isolation. Current recommended practice suggests otherwise. Teachers are urged to select instructional objectives based on their importance in improving the child's functioning in present environments and ability to participate in future age-appropriate environments (Noonan \& McCormick, 1993; Voeltz \& Evans, 1983). In addition, teachers of children with special needs are urged to teach skills not out of context but in sequence with other skills as they would typically occur (Sailor \& Guess, 1983) and at the times when they are most needed (Hart \& Risley, 1975) using natural stimuli and consequences (Falvey, Brown, Lyon, Baumgart, \& Schroeder, 1980). For example, instead of teaching students to identify colors through the use of flash cards, educators can teach color concepts during snack time, story time, free play, and at other times during the day when children initiate language. Instruction based in meaningful contexts is most likely to generalize to new settings and be maintained over time by naturally occurring contingencies.

\section{Myth \#5: ECSE Recommended Practices Are Com- pletely Behaviorally Based and Do Not Incorporate De- velopmental Principles}

Because many early childhood special education programs and practices have grown out of behavioral techniques pioneered with older students with mental retardation, many people believe that ECSE still is based exclusively on principles of applied behavior analysis. In reality, current ECSE practice is grounded philosophically by three curriculum models: developmental, developmental-cognitive, and behavioral (Noonan \& McCormick, 1993). The developmental model, which is based on early research on child growth and maturation (Gesell \& Amatruda, 1947), focuses on teaching children skills across several domains (e.g., motor, adaptive, social, and communication) according to the sequence followed by typically developing young children. The developmental-cognitive model, which is based on Piagetian theory (Piaget, 1952), emphasizes cognitive development and instruction that "challenges" children to move on to the next stage. The behavioral model, which is based on the learning principles defined by Skinner, Bijou, and Baer, focuses on shaping children's behavior through systematic procedures and careful arrangement of the environment. Clearly, although these models are presented here as distinct, each is evolving and all appear to be converging toward more naturalistic and functional approaches.

\section{Summary}

In summary, just as with DAP, many misconceptions exist about what is acceptable and recommended practice for serving young children with disabilities. These myths, like those associated with DAP, stand in the way of attempts to determine how early childhood educators can work together with professionals in early childhood special education in teaching young children with special needs in inclusive settings. Once these misconceptions have been clarified, the next step is to determine the real differences that separate DAP and ECSE recommended practices.

\section{DIFFERENCES BETWEEN DAP AND ECSE}

A considerable amount of overlap exists between DAP and those practices recommended in ECSE, but a few key features reveal differences between these sets of practices. Most of the distinctions are merely differences in emphasis; some, however, cut to divergent premises.

\section{Role of Educational Intervention}

One fundamental philosophical difference between ECE and ECSE concerns the relative importance placed on educational intervention and the histories of these two fields regarding changing children's trajectories of development (Carta, Schwartz, Atwater, \& McConnell, 1991). Underlying ECSE is the premise that children with special needs should receive intervention as early as needed. This premise is based on the substantial body of literature documenting that children's delay in acquiring early skills may have serious negative consequences: They may develop secondary disabilities, they may have difficulty acquiring more complex skills, and their future educational and occupational opportunities may be compromised (Meisels \& Shonkoff, 1990). DAP, in contrast, grew out of a concern that early childhood programs too often overemphasized accelerating the development of young children. Early education programs have therefore chosen to de-emphasize vertical learning, or preparing children for future expectations by teaching them skills according to a sequence. Instead, these programs have often emphasized horizontal learning, or helping children gain concepts through their experiences on a moment-bymoment basis (Johnson \& McChesney Johnson, 1992). The assumption of the DAP model is that in a responsive environment that follows a developmentally appropriate curriculum, children will naturally achieve the important goals of self-esteem, independence, and advanced social relationships. Most of the other differences between DAP and ECSE recommended practices have grown out of this philosophical difference. 


\section{Process of Individualization}

A key distinction between DAP and ECSE practice involves the role of individualization. The importance of individualization is a fundamental premise of ECSE programs. Legal mandates require that programs for young children with special needs be developed, implemented, and evaluated for individual children. These programs must include individualized teaching plans consisting of goals and objectives based on a careful analysis of the child's strengths and weaknesses and on skills required for future school and nonschool environments. But in addition to the legal mandate, ECSE affords a technology of individualization. ECSE methods for individualization include task analysis (breaking tasks down into their component parts), adaptation of activities and materials, use of a range of prompts for directing children's behavior, and the employment of a range of options for motivating children. All of these practices are founded on systematic assessment procedures that are used to determine the most appropriate means of teaching the individual child (Bailey \& Wolery, 1989).

The process of individualization is defined somewhat differently in early childhood education in general and within the DAP guidelines more specifically. The concept of individualization in DAP focuses on the need for early childhood programs to provide activities that are wide-ranging enough to address a broad range of children's interests and skills. Bredekamp (1993) pointed out that although early childhood education programs place value on the individual child, they have been much less systematic in the determination of goals for individual children. The homogeneous nature of typical preschool programs in the past has led teachers to base their teaching on normative expectations; however, the cultural, linguistic, and developmental diversity represented in early childhood programs today demands greater emphasis on meeting children's individual needs.

\section{Role of Assessment}

A related issue that also separates DAP and ECSE practice is the manner and frequency in which assessment is conducted. In ECSE, assessment must be derived from many sources, be carried out across settings, and be frequent enough to monitor children's progress toward their individual goals and objectives. Assessment is the bedrock of appropriate individualization. Although both the DAP guidelines and ECSE recommended practices stress the need to move beyond standardized assessments to provide meaningful information about young children, the DAP guidelines do not go as far as ECSE practices in articulating the need for comprehensive assessment. ECSE practices suggest that assessment should be conducted by professionals from diverse disciplines, should involve a variety of measures including observation in natural settings, should be linked to the curriculum, and should reflect input from the child's family (Kaminski \& Carey, 1993). These assessment considerations are not incompatible with DAP guidelines; they are simply unstated in the DAP document. These elements are critical, however, for assessment to yield meaningful and ecologically relevant information.

\section{Preparation for Transition}

Also important in ECSE is to prepare children for future environments (Carta, Atwater, Schwartz, \& Miller, 1990; Fowler, Schwartz, \& Atwater, 1991). Such preparation serves the goal of facilitating a child's progress through a natural succession of inclusive educational environments. Because one of the goals of ECSE is to help children flourish in those environments, it is important to prepare children in advance in addition to adapting the environment in which the child is eventually placed. Children with disabilities often have problems with major educational transitions because they have not had sufficient opportunities to learn and practice skills that will be expected in the future environment (Carta, Sainato, \& Greenwood, 1988). Moreover, when children begin at a disadvantage relative to their classmates, they have a greater likelihood of falling farther behind with time. An accumulating body of evidence indicates that interventions can be effective in counteracting such declines and helping children make transitions successfully (Carta, Atwater, \& Schwartz, 1992; Noonan et al., 1992; Rule, Fiechtl, \& Innocenti, 1990).

Some people contend that preparing children for future environments contradicts DAP standards. Early childhood educators have sometimes viewed preparation for kindergarten as an inappropriate downward shifting of academic standards from elementary grades to the preschool levels. Early childhood educators share the concern for successful transitions but emphasize adapting the kindergarten environment to meet children's special needs rather than requiring the children to adapt to inappropriate expectations (NAEYC, 1990). Clearly, both advance preparation for transition and adaptations of the inclusive setting are important for successful transitions.

\section{Role of Families}

Another distinction between ECSE recommended practices and DAP involves the role of families. As with the other distinctions, the difference is one of emphasis rather than a fundamental gap between approaches. The recently developed recommended practices developed by the Division of Early Childhood within the Council for Exceptional Children (DEC Task Force on Recommended Practices, 
1993 ) is strongly infused with principles of family centeredness (McLean \& Odom, 1993). In ECSE, the emphasis on family involvement has grown considerably over the past 20 years. The current recommendation and the legal mandate in ECSE is for the family to be at the center of the assessment process and to participate fully in decision making regarding the intervention process (Vincent \& Beckett, 1993).

The importance of parent and family involvement in early childhood programs is not as strongly articulated in the DAP guidelines as in ECSE practice. The DAP document indicates that "parents have both the right and the responsibility to share in decisions about their children's care and education" (Bredekamp, 1987, p. 12), but it does not offer concrete examples of how this shared decision making will take place (Powell, 1994). According to Powell (1994), "Professionals are seen as resourceful, and the flow of influence is one way, from professional to client. This is in contrast with a collaborative relationship in which both parents and staff have equal status in defining the nature of a situation, goals of the work, the problem-solving process, and the evaluation of its success" (p. 176). Despite this apparent ambivalence in DAP regarding the role of parents, the field of early childhood education has a strong tradition and is engaged in some important new trends in including parents' perspectives and being responsive to families' needs. Headstart has long mandated parent participation in decision making with regard to children's programs. Additionally, the developers of many early childhood programs are taking increased responsibility in making sure the programs provide families with comprehensive services and support (Bredekamp, 1993). This area is one in which ECSE can contribute much to early education, but it is also one in which even ECSE has much to learn.

\section{Necessity of Interagency Collaboration}

Another difference in emphasis between ECSE practice and DAP guidelines is the necessity for interagency collaboration. One of the hallmarks of ECSE practice since its inception has been the development and implementation of programs for children based on the input of people from many disciplines. Commonly, representatives from many disciplines and agencies are involved in the preparation of a child's Individual Education Plan or Individual Family Service Plan. Such collaboration is not commonplace in early childhood programs (McLean \& Odom, 1993). In most cases, the needs of typically developing children are well served within a single high-quality early childhood setting. ECE professionals have, however, begun to realize the need for expanding the level of support to families. The multiple needs of many families will require that all early childhood professionals augment their competence in working with representatives of other disciplines. In addition, the educa- tion of young children with special needs in inclusive settings will require that ECE professionals like their ECSE counterparts collaborate and communicate across many disciplines (Odom \& McEvoy, 1990; Stayton \& Miller, 1993).

\section{Importance of Outcomes}

Another distinction between ECSE practices and the DAP guidelines concerns the requirement that programs be outcome-based. In ECSE, this principle is of paramount importance. Programs must have specific criteria, procedures, and timelines to ensure that individual children are making progress toward their specific goals and objectives. Programs providing educational services to young children with special needs have the burden of proof to substantiate that the programs are beneficial (PL 99-457). This principle of accountability is perhaps the area of greatest discrepancy between what is required in ECSE and what defines early childhood education practices. The DAP guidelines were developed in part in reaction to an "accountability culture" (Hatch \& Freeman, 1988). Programs that serve young children with special needs, however, need to demonstrate that they are moving children forward toward the goal of increasing normalization. Thus, teachers instructing young children with disabilities must frequently assess the program's effectiveness in terms of the child's progress toward identified goals and, when needed, refine or adjust the program to strengthen its effectiveness (Bagnato \& Neisworth, 1991). Although ECE programs have not emphasized outcomes to the same degree as ECSE programs, leaders in ECE recognize that ECSE has much to offer in this regard (Bredekamp, 1993).

\section{APPLICABILITY OF DAP FOR YOUNG CHILDREN WITH DISABILITIES}

In accordance with the Americans With Disabilities Act (ADA) (PL 101-336), all early childhood programs must be able to serve children with disabilities. This act, in conjunction with the Individuals With Disabilities Education Act, means that full inclusion of young children with special needs will become a reality. But as the fields of early childhood education and early childhood special education begin to come together, will members of the two fields reach agreement about the applicability of DAP for children with disabilities? In light of the number of differences in content and emphasis between DAP and ECSE, are the DAP guidelines applicable for teaching young children with special needs? Certainly. All early education programs whether they are implemented in inclusive or specialized settings can and should use developmentally appropriate practices as the context for teaching young children with disabilities. It is 
clear, however, that for some children with disabilities, and for some specific situations, the practices that were outlined in the original DAP guidelines may not be sufficient for guiding the manner in which programs and services are provided (Safford, 1989; Wolery et al., 1992). Some children and some situations may require a more direct approach to intervention wherein more careful planning, structure, and regular program monitoring are provided than is detailed in the DAP guidelines. Even the leadership of NAEYC has agreed that the DAP guidelines are not adequate on their own to address the special needs of some young children. But as ECSE and ECE professionals are joining forces to develop inclusive settings for young children with disabilities, the utility of the DAP guidelines for planning and implementing programs for children with diverse abilities will be increasingly tested. As these groups of practitioners move together, they will be assisted by two important factors: (A) There are many areas of overlap between DAP and ECSE; and (B) There are many ECSE practices that stand the test of developmental appropriateness.

\section{Commonalities Between ECSE and DAP}

As the fields of early childhood education and early childhood special education come together to create effective programs for young children with disabilities in inclusive settings, it is important to realize the common ground shared between ECSE and DAP. The overlapping areas can become an important starting point for discussions about how to develop and evaluate programs for individual children.

\section{Importance of Individualization}

The most fundamental principle of ECSE is the importance of individualization (Bricker \& Veltman, 1990). Indeed, the ECSE mandate is to provide programs that meet the specific needs of children and their families. The careful planning of classroom environments and teaching procedures to address these needs is the linchpin of ECSE. Although the DAP guidelines, as mentioned previously, do not contain specifics about how to individualize, their stated intent was to emphasize the notion of individual appropriateness as well as that of age appropriateness (Bredekamp, 1987, 1993). All children can be served in developmentally appropriate contexts, but special adaptations sometimes are necessary for them to be active participants in educational settings with peers without disabilities. The leadership of NAEYC confirmed this basic premise in the statement that "early childhood education for all children could be improved if the prevailing support for and understanding of developmentally appropriate practice gave greater emphasis to assessing and planning for individual children" (Bredekamp, 1993, p. 265).

\section{Need for More Authentic Assessment}

Another area of joint concern is the need for more authentic assessment of young children. Both DAP and ECSE share the view that assessment must become more naturalistic and multidimensional than traditional norm-based assessment if it is to have instructional utility for providing individually appropriate services to young children. Both DAP and ECSE recommend moving beyond traditional standardized assessments to obtain information about children's outcomes resulting from participation in programs. The DAP guidelines state that "scores derived from psychometric tests should never be used as the sole criteria for recommending enrolling or retention in a program or placement in special or remedial classes" (Bredekamp, 1987, p. 13). Other position papers have also contained warnings about the inadequacies and dangers of inappropriate assessment practices (Bredekamp \& Rosegrant, 1992; NAEYC \& National Association of Early Childhood Specialists in State Departments of Education [NAECS/SDE], 1991; Perrone, 1991). Early childhood professionals have advocated for "authentic assessment," the "process of observing, recording, and otherwise documenting the work that children do and how they do it as a basis for educational decisions that affect those children. Ö Authentic assessment provides continuous qualitative information that can be used by the teacher to guide the instruction of individuals" (Puckett \& Black, 1994, p. 22).

In ECSE, too, a variety of more naturalistic methods of assessment have been advocated in place of traditional standardized assessment. These include arena, play-based, ecological or ecobehavioral assessment (Carta \& Greenwood, 1985). With all of these approaches, children are assessed while engaged in natural as opposed to clinical settings. In arena assessment, representatives from different disciplines gather together to assess a single child (Wolery \& Dyk, 1984). Transdisciplinary play-based assessment (TPBA) is an example of an assessment that uses an arena format (Linder, 1990). With TPBA, professionals plan and implement observations of a single child engaged in structured and unstructured play, interacting with a peer and a caregiver, engaged in motor activities, and having a snack. These situations allow the team members to record and share their observations about the child's spontaneous behaviors when engaged in typical activities. Clearly, members of the fields of early education and early childhood special education share concern about the misuse of standardized tests. Professionals in both fields realize that testing young children poses special problems for the assessor, and as such it is important to include multiple sources of information, measure repeatedly, and conduct assessments in settings as natural as possible.

Another measurement consideration shared by members of both fields is the need to employ assessments that are functional. ECSE, for example, has long advocated the use of cur- 
riculum-referenced measures that provide information about a child's status relative to a prespecified curriculum sequence instead of in relationship to other children. Such measures are useful for identifying individual children's intervention objectives and for tracking their progress within the curriculum. Examples of this type of measure include the Carolina Curriculum for Handicapped Infants and Infants at Risk (Johnson-Martin, Jens, \& Attemeier, 1986), the Battelle Developmental Inventory (Newborg, Stock, Wnek, Guidubaldi, \& Svinicki, 1984), and the Assessment, Evaluation, and Programming System for Infants and Children (Bricker, 1993). This same basic notion of integrating curriculum and assessment was stated in the curriculum and assessment guidelines recently published by NAEYC: "Curriculum and assessment are integrated throughout the program; assessment is congruent with and relevant to the goals, objectives, and content of the program. Assessment results in benefits to the child such as needed adjustments in the curriculum or more individualized instruction and improvements in the program" (NAEYC, NAECS/SDE, 1991, p. 32). Thus, it appears as though agreement exists between ECSE and DAP on the basic notion of integrating assessment and curriculum. What remains to be determined, however, are the objectives that should be included in that integration.

One final innovation in assessment is the use of ecobehavioral assessment (Carta \& Greenwood, 1985). This type of measurement allows for the moment-by-moment recording of children's behavior in relationship to objects, events, and persons in their natural environments.

\section{Importance of Active Engagement}

Almost every theory of development emphasizes the importance of active engagement. Notable among them are the Piagetian notion that children discover through active exploration of their environments and the learning theorist notion that children's progress is enhanced through active time spent in meaningful tasks. It is not surprising, then, that the importance of active engagement is stated specifically in the DAP guidelines (Bredekamp, 1987; NAEYC, NAECS/ SDE, 1991) and is also a guiding principle of effective ECSE practices (Jones \& Warren, 1991; McWilliam, Trivette, \& Dunst, 1985). ECE and ECSE professionals may plan for active engagement in different ways, however, because some young children with disabilities do not become spontaneously engaged in their environments (Peck, 1985; Weiner $\&$ Weiner, 1974). Therefore, a principal goal of early intervention with such children is to facilitate their active engagement across materials, activities, and environments through systematic and individualized instruction (Nordquist \& Twardosz, 1990; Wolery et al., 1992). These children may need to be taught some rudimentary skills in interacting with toys, playing with peers, and communicating with others so that eventually they will be able to spontaneously engage their environment.

\section{Emphasis on Social Interaction}

Individuals concerned with the early education of young children with and without disabilities support the importance of the development of social competence (Hartup, 1983; Odom, McConnell, \& McEvoy, 1992). A large body of literature substantiates that typically developing young children advance their language, cognitive, and social skills through their increasingly complex interaction with peers (Gottman, 1983; Murray, 1972). Not surprisingly, social interaction is an area of emphasis in many ECSE programs (Odom et al., 1992). Children with disabilities often exhibit deficits in their degree of involvement in peer interactions, and specific training often is required to enhance their social competence (McEvoy, Odom, \& McConnell, 1992). So, although both ECSE and DAP share the perspective that social interaction is important in the education of young children, ECSE has emphasized the inclusion of specific procedures for developing social competence in preschool settings. Early childhood educators have also begun to develop intervention techniques to promote social competence in light of "compelling evidence that if teachers or other adults do not intervene to support the social development of socially isolated young children, these children will likely continue to be rejected or neglected by their peers and will have difficulty adjusting in later life" (Bredekamp, 1993, p. 267).

\section{Importance of Cultural Diversity}

Both ECSE and ECE professionals recognize that cultural differences must be considered in programs serving young children (Derman-Sparks and the A.B.C. Task Force, 1989; Lynch \& Hanson, 1992). Both fields share the perspective that providing multicultural experiences in programs is necessary to accommodate individual differences and to support the integrity of the family backgrounds and cultures of all the children. Both fields also share the concern about the cultural appropriateness of assessment measures. Furthermore, ECSE programs have adopted an expanded notion of cultural sensitivity and have begun to address ways for teachers to become cross-culturally competent when working with families. Cross-cultural competence is more than acknowledging the value of all cultures and understanding and appreciating cultural differences. It involves learning specific skills and obtaining culture-specific information that can help one understand the values and attitudes that shape families' worldviews (Lynch \& Hanson, 1992). Such understanding of cultural diversity is an essential skill for early interventionists working with family members in selecting goals and developing programs attuned to a family's needs and values. In the ECE field, many persons have urged for a recognition of 
the existence of different cultural interpretations of development and an examination of the implications of these cultural differences for the classroom (Au \& Kawakami, 1991; Bowman \& Stott, 1994).

The areas of overlap depicted here represent only a fraction of the many areas in which ECSE and DAP converge. Obviously, the areas of convergence hold the greatest potential as starting points for ECSE and ECE professionals to join forces in the challenge of providing developmentally appropriate programs to children with diverse abilities in inclusive settings. Even more specifically, however, these professionals will be assisted in their endeavor by recognizing that many traditional ECSE procedures not only have a proven record of effectiveness but also appear to be developmentally appropriate.

\section{Instructional Procedures That "Bridge the Gap"}

As the field of early childhood special education and early childhood education grow ever closer, a number of individuals have identified specific instructional strategies that both are effective for addressing the needs of young children with disabilities and appear to be acceptable within the DAP guidelines (Atwater, Carta, Schwartz, \& McConnell, 1994; Cavallaro, Haney, \& Cabello, 1993; Wolery \& Fleming, 1993). These practices are presented here not as the absolute answer for determining developmentally appropriate procedures for children with disabilities (because all procedures must be scrutinized for their individual appropriateness) but because they are illustrations of approaches on which members of both fields can agree and because they are approaches that can act as starting points for further collaborative program development.

\section{Embedding Instructional Objectives Within Activities}

One instructional procedure for addressing the special needs of children with disabilities that may fit easily in typical early childhood settings is activity-based intervention. With this approach, teachers provide planned opportunities for the teaching and practice of specific skill objectives within typical classroom routines and play activities (Bricker \& Cripe, 1992). The activities are organized as much as possible to encourage child engagement through the natural structure and consequences of involvement in the activity rather than specific direction from the teacher. Using this approach, a teacher can organize individual activities that address multiple objectives for a single child or that incorporate different objectives for many children.

\section{Incidental Teaching}

A well-validated group of strategies for promoting children's language and social skills, incidental teaching proce- dures are a natural fit with DAP guidelines because they are based on child initiations (Brown, McEvoy, \& Bishop, 1991; Hart, 1985). Although the term "incidental teaching" refers to an entire group of naturalistic intervention procedures, the common thread of these procedures is that they all make use of an instructional sequence that begins when a child initiates an interaction by demonstrating an interest in an activity, a specific material, or a peer or other person in the environment. The adult then builds on this interest and uses modeling or some other strategy to elicit a more sophisticated response from the child. Among the techniques documented to increase children's language skills are joint attention and topic continuation or talking about topics in which the child has a demonstrated interest (Tomasello \& Farrar, 1986; Yoder \& Davies, 1990); expansions, or replying to a child with more elaborate syntactically correct versions of his or her utterances; recasts, or repeating a child's utterance that changes the structure of the utterance (Nelson, 1977); and confirming children's requests (Yoder \& Kaiser, 1989). All of these procedures involve using the child's interests as the basis for interaction and then providing verbal responses that support more advanced responses by the child.

\section{Arranging the Environment to Promote Specific Behaviors}

Another instructional procedure that may fit well with DAP guidelines is arranging the classroom environment to set the stage for specific behaviors. For example, children are more likely to engage in social interactions when specific toys are provided (Quilitch \& Risley, 1973), when peers are available and proximal (Spiegel-McGill, Bambara, Shores, \& Fox, 1984), and within certain types of activities (Sainato \& Carta, 1992). Similarly, children's language interactions are promoted in specific types of environmental arrangements, with certain materials, or in certain activities (Notari \& Cole, 1993). Environmental arrangements have not had a consistent "track record," however (Odom \& Brown, 1993), and clearly, with this intervention as well as all others, it is imperative that the teacher monitor progress continuously and make necessary changes in any program that does not appear to be effective.

\section{Using Environmental Prompts}

Environmental prompts are also commonly used for promoting children's independent performance of a behavior. A typical goal is to have children with disabilities practice behaviors in the absence of adult prompting. Environmental cues can be used on a temporary or permanent basis to assist children in remembering a sequence of steps or activities, the direction to the next center, or the expected behaviors in a certain classroom area. For example, a pictorial sequence might be used to remind children of the steps involved during a clean-up transition, red and green footprints on a stair- 
well can help children remember to alternate feet when going up and down stairs, pictures on a poster can depict the rules for free-play time. Teachers need to be aware, however, that using environmental prompts will not be effective in helping children remember sequences of behaviors unless they are taught the sequence and how to follow the environmental prompt. In addition, teachers should monitor the effectiveness of the environmental prompts and develop more direct approaches to teaching when necessary, and they should, in time, fade the environmental prompts so that independent performance will truly be demonstrated.

\section{Using Peer-Mediated Strategies}

A variety of strategies that incorporate peers as instructional agents are available for teaching many behaviors but most especially social interaction skills. These strategies vary considerably in level of intensity, amount of structure required, and level of training and resources needed (Odom \& Brown, 1993). Because learning from peers is a principal rationale for including children with special needs in typical early childhood settings, using peers to facilitate learning and integrating is an obvious instructional strategy. In determining how peers will be employed to this end, however, teachers must realize that the overwhelming evidence suggests that mere physical proximity to peers is insufficient to promote social interaction (Odom \& McEvoy, 1988). Among the types of procedures available that employ peers are group affection activities, or activities that provide children with opportunities to engage in social behaviors such as hugs or "high fives" to which their peers are likely to respond positively; peer-initiation interventions, or training peers to initiate special social behaviors such as sharing and physical assistance (Strain \& Odom, 1986); and cooperative learning, or instructional situations that encourage social interaction through the interdependence of the group members (Johnson \& Johnson, 1986; Noonan \& McCormick, 1993). In determining how to select and individualize interventions, teachers should follow the general guideline of using interventions that require the least amount of change in class routine, determining if more intense intervention is necessary, and then providing more structure and direct teaching of objectives when more naturalistic approaches prove ineffective.

\section{CONCLUSION}

Can children with disabilities be instructed using developmentally appropriate guidelines? Yes. But the applicability of the DAP guidelines can be truly ascertained only by evaluating their translation to practice to particular young children with disabilities. The manner in which DAP is individualized to suit the unique needs of specific children will help us expand our notions about effective intervention and what is developmentally appropriate for all children. In this regard, McCollum and Bair (1994) state: "We believe that what will be learned is that the definition lies not in particular practices, but in the match between a particular child, a particular task, and the balance of challenge and support provided" (p. 103). Learning how to create that balance for the diversity of children in our schools will be the challenge faced by early childhood education and early childhood special education professionals as they strive for more effective inclusive programs and practices.

\section{REFERENCES}

Atwater, J. B., Carta, J. J., Schwartz, I. S., \& McConnell, S. R. (1994). Blending developmentally appropriate practice and early childhood special education: Redefining best practice to meet the needs of all children. In B. L. Mallory \& R. S. New (Eds.), Diversity and developmentally appropriate practices ( $\mathrm{pp}$. 185-201). New York: Teachers College, Columbia University.

Au, K.H., \& Kawakami, A. J. (1991). Culture and ownership. Childhood Education, 67, 280-284.

Bagnato, S. J., \& Neisworth, J. T. (1991). Assessment for early intervention: Best practices for professionals. New York: Guilford Press.

Bailey, D. B., \& Wolery, M. (Eds.). (1989). Assessing infants and preschoolers with handicaps. Columbus, $\mathrm{OH}$ : Charles E. Merrill.

Bowman, B. T., \& Stott, F. M. (1994). Understanding development in a cultural context: The challenge for teachers. In B. L. Mallory \& R. S. New (Eds.), Diversity and developmentally appropriate practices (pp. 119-134). New York: Teachers College, Columbia University.

Bredekamp, S. (Ed.). (1987). Developmentally appropriate practice in early childhood programs serving children from birth through age 8. Washington, DC: National Association for the Education of Young Children.

Bredekamp, S. (1993). The relationship between early childhood education and early childhood special education: Healthy marriage or family feud? Topics in Early Childhood Special Education, 13, 258-273.

Bredekamp, S., \& Rosegrant, T. (Eds.). (1992). Reaching potentials: Appropriate curriculums and assessment for young children (Vol. 1). Washington, DC: National Association for the Education of Young Children.

Bricker, D. (1993). AEPS curriculum for birth to three years (Vol. 1). Baltimore: Brookes.

Bricker, D., \& Cripe, J. J. (1992). An activity-based approach to early intervention. Baltimore: Brookes.

Bricker, D., \& Veltman, M. (1990). Early intervention programs: Child-focused approaches. In S. J. Meisels \& J. P. Shonkoff (Eds.), Handbook of early childhood intervention (pp. 373-399). New York: Cambridge University Press.

Brown, W. H., McEvoy, M. A., \& Bishop, N. (1991). Incidental teaching of social behavior. Teaching Exceptional Children, 24(1), 35-38 
Carta, J. J., Atwater, J. B., \& Schwartz, I. S. (1992, May). Classroom survival skills interventions: Demonstration of short-and long-term effects. Paper presented at the meeting of the Association for Behavior Analysis, San Francisco, CA.

Carta, J. J., Atwater, J. B., Schwartz, I. S., \& Miller, P. A. (1990). Application of ecobehavioral analysis to the study of transitions across early education. Education and Treatment of Children, 13, 298-311.

Carta, J. J., \& Greenwood, C. R. (1985). Ecobehavioral assessment: A methodology for expanding the evaluation of early intervention programs. Topics in Early Childhood Special Education, 5(4), 88-104.

Carta, J. J., Sainato, D. M., \& Greenwood, C. R. (1988). Advances in the ecological assessment of classroom instruction for young children with handicaps. In S. L. Odom \& M. B. Karnes (Eds.), Early intervention for infants and children with handicaps: An empirical base (pp. 217-240). Baltimore: Brookes.

Carta, J. J., Schwartz, I. S., Atwater, J. B., \& McConnell, S. R. (1991). Developmentally appropriate practice: Appraising its usefulness for young children with disabilities. Topics in Early Childhood Special Education, 11(1), 1-20.

Cavallaro, C. C., Haney, M., \& Cabello, B. (1993). Developmentally appropriate strategies for promoting full participation in early childhood settings. Topics in Early Childhood Special Education, 13, 293-307.

DEC Task Force on Recommended Practices (1993). DEC recommended practices: Indicators of quality in programs for infants and young children with special needs and their families. Reston, VA: Author.

Delpit, L. (1988). The silenced dialogue: Power and pedagogy in educating other people's children. Harvard Educational Review, 58(3), 290-298.

Derman-Sparks and the A. B. C. Task Force (1989). Anti-bias curriculum: Tools for empowering young children. Washington DC: National Association for the Education of Young Children.

Elkind, D. (1987). Miseducation: Preschoolers at risk. New York: Knopf.

Falvey, M., Brown, L., Lyon, S., Baumgart, D., \& Schroeder, J. (1980). Strategies for using cues and correction procedures. In W. Sailor, B. Wilcox, \& L. Brown (Eds.), Methods of instruction for severely handicapped students (pp. 109-133). Baltimore: Brookes.

Fowler, S. A., Schwartz, I., \& Atwater, J. B. (1991). Perspectives on the transition from preschool to kindergarten for children with disabilities and their families. Exceptional Children, 58, 136145.

Gesell, A., \& Amatruda, C. S. (1947). Developmental diagnosis. New York: Paul B. Holden.

Goodman, J. (1992, January 7). Wrong way to educate the handicapped. The Washington Post, p. A19.

Gottman, J. M. (1983). How children become friends. Monographs of the Society for Research in Child Development, 48 (Serial No. 201).

Grossen, B. (1993). Child-directed teaching methods: A discriminatory practice of Western education. Effective School Practices, 12(2), 9-20.
Hart, B. M. (1985). Naturalistic language training techniques. In S. F. Warren \& A. K. Rogers-Warren (Eds.), Teaching functional language (pp. 63-88). Austin, TX: PRO-ED.

Hart, B., \& Risley, T. (1975). Incidental teaching of language in the preschool. Journal of Applied Behavior Analysis, 8, 411-420.

Hartup, W. W. (1983). Peer relations. In M. Heatherington (Ed.), Handbook of child psychology (Vol. 4, pp. 103-196). New York: John Wiley \& Sons.

Hatch, J. A., \& Freeman, E. B. (1988). Who's pushing whom? Stress and kindergarten. Phi Delta Kappan, 70, 145-147.

Jipson, J. (1991). Developmentally appropriate practice: Early childhood education as development-Critique of the metaphor Early Education and Development, 2(2), 137-152.

Johnson, D., \& Johnson, D. (1986). Mainstreaming and cooperative learning strategies. Exceptional Children, 52, 553-561.

Johnson, J. E., \& McChesney Johnson, K. (1992). Clarifying the developmental perspective in response to Carta, Schwartz, Atwater, \& McConnell. Topics in Early Childhood Special Education, 12, 439-457.

Johnson-Martin, N. M., Jens, K. G., \& Attermeier, S. M. 1986). Carolina curriculum for handicapped infants and infants at risk. Baltimore: Brookes.

Jones, H., \& Warren, S. (1991). Enhancing engagement in early language teaching. Teaching Exceptional Children, 23(4), 48-50.

Kaminski, R., \& Carey, S. (1993). Developmentally appropriate practice and early childhood special education: Bridging the gap. Effective School Practices, 12(2), 81-86.

Kessler, S. (1991). Alternative perspectives on early childhood education. Early Childhood Research Quarterly, 6, 183-197.

Kostelnik, M. J. (1992). Myths associated with developmentally appropriate programs. Young children, 47(4), 17-23.

Linder, T. (1990). Transdisciplinary play-based assessment. Baltimore: Brookes.

Lubeck, S. (1994). The politics of developmentally appropriate practice: Exploring the issues of culture, class, and curriculum. In B. L. Mallory \& R. S. New (Eds.), Diversity and developmentally appropriate practices (pp. 7-43). New York: Teachers College, Columbia University.

Lynch, E. W., \& Hanson, M. J. (1992). Steps in the right direction: Implications for interventionists, In E. W. Lynch \& M. J. Hanson (Eds.), Developing cross-cultural competence: A guide for working with young children and their families (pp. 355-370). Baltimore: Brookes.

McCollum, J. A., \& Bair, H. (1994). Research in parent-child interaction: Guidance in developmentally appropriate practice for young children with disabilities. In B. L. Mallory \& R. S. New (Eds.), Diversity and developmentally appropriate practices (pp. 84-106). New York: Teachers College, Columbia University.

McEvoy, M. A., Odom, S. L., \& McConnell, S. R. (1992). Peer social competence intervention for young children with disabilities. In S. L. Odom, S. R. McConnell, \& M. A. McEvoy (Eds.), Social competence of young children with disabilities (pp. 113134). Baltimore: Brookes.

McLean, M. E., \& Odom, S. L. (1993). Practices for young children with and without disabilities: A comparison of DEC and NA- 
EYC identified practices. Topics in Early Childhood Special Education, 13, 274-292.

McWilliam, R. A., Trivette, C. M., \& Dunst, C. J. (1985). Behavior engagement as a measure of the efficacy of early intervention. Analysis and Intervention in Developmental Disabilities, 5, 59-71.

Mallory, B. L. (1994). Inclusive policy, practice, and theory for young children with developmental differences. In B. L. Mallory \& R. S. New (Eds.), Diversity and developmentally appropriate practices (pp. 1-14). New York: Teachers College, Columbia University.

Meisels, S. J., \& Shonkoff, J. P. (Eds.). (1990). Handbook of early childhood intervention. Cambridge, MA: Harvard University Press.

Murray, F. (1972). The acquisition of conversation through social interaction. Developmental Psychology, 6, 1-6.

National Association for the Education of Young Children (1990). NAEYC position statement on school readiness. Young Children, 46(1), 21-23.

National Association for the Education of Young Children and the National Association of Early Childhood Specialists in State Departments of Education (1991). Guidelines for appropriate curriculum content and assessment in programs serving children ages 3 through 8. Young Children, 46(3), 21-38.

Nelson, K. E. (1977). Facilitating children's syntax acquisition. Developmental Psychology, 13, 101-107.

New, R. S., \& Mallory, B. L. (1994). Introduction: The ethics of inclusion. In B. L. Mallory \& R. S. New (Eds.), Diversity and developmentally appropriate practices (pp. 1-14). New York: Teachers College, Columbia University.

Newborg, J., Stock, J., Wnek, L., Guidubaldi, J., \& Svinicki, J. (1984). Battelle Developmental Inventory. Allen, TX: DLM Teaching Resources.

Noonan, M. J., \& McCormick, L. (1993). Early intervention in natural environments: Methods and procedures. Pacific Grove, CA: Brooks/Cole.

Noonan, M. J., Ratokalau, N. B., Lauth-Torres, L., McCormick, L., Esaki, C. A., \& Claybaugh, K. W. (1992). Validating critical skills for preschool success. Infant-Toddler Intervention: The Transdisciplinary Journal, 2, 187-203.

Nordquist, V. M., \& Twardosz, S. (1990). Preventing behavior problems in early childhood special education classrooms through environmental organization. Education and Treatment of Children, 13, 274-287.

Notari, A., \& Cole, K. (1993). Language intervention: Research and implications for service delivery. In C. A. Peck, S. L. Odom, \& D. D. Bricker (Eds.), Integrating young children with disabilities into community programs (pp. 17-38). Baltimore: Brookes.

Odom, S. L., \& Brown, W. H. 1993). Social interaction skills interventions for young children with disabilities in integrated settings. In C. A. Peck, S. L. Odom, \& D. D. Bricker (Eds.), Integrating young children with disabilities into community programs (pp. 39-64). Baltimore: Brookes.

Odom, S. L., McConnell, S. R., \& McEvoy, M. A. (1992). Peer-related social competence and its significance for young children with disabilities. In S. L. Odom, S. R. McConnell, \& M. A. McEvoy (Eds.), Social competence of young children with disabilities (pp. 3-37). Baltimore: Brookes.

Odom, S. L., \& McEvoy, M. A. (1988). Integration of young children with handicaps and normally developing children. In S. Odom \& M. B. Karnes (Eds.), Early intervention for infants and children with handicaps: An empirical base (pp. 241-267). Baltimore: Brookes.

Odom, S. L. \& McEvoy, M. A. (1990). Mainstreaming at the preschool level: Potential barriers and tasks for the field. Topics in Early Childhood Special Education, 10(2), 48-61.

Peck, C. (1985). Increasing opportunities for social control by children with autism and severe handicaps: Effects on student behavior and perceived classroom climate. Journal of the Association for Persons With Severe Handicaps, 10, 183-193.

Perrone, V. (1991). On standardized testing: A position paper. Childhood Education, 67(3), 132-142.

Piaget, J. (1952). The origins of intelligence in children. New York: Norton.

Powell, D. R. (1994). Parents, pluralism, and the NAEYC statement on developmentally appropriate practice, In B. L. Mallory \& R. S. New (Eds.), Diversity and developmentally appropriate practices (pp. 166-182). New York: Teachers College, Columbia University.

Puckett, M. B., \& Black, J. K. (1994). Authentic assessment of the young child: Celebrating development and learning. New York: Macmillan College Publishing.

Quilitch, H. R., \& Risley, T. R. (1973). The effects of play materials on social play. Journal of Applied Behavior Analysis, 6, 573-578.

Richarz, S. (1993). Innovations in early childhood education: Models that support the integration of children of varied developmental levels. In C. A. Peck, S. L. Odom, \& D. D. Bricker (Eds.), Integrating young children with disabilities into community programs (pp. 83-107). Baltimore: Brookes.

Rule, S., Fiechtl, B. J., \& Innocenti, M. S. (1990). Preparation for transition to mainstream post-preschool environments: Development of survival skills curriculum. Topics in Early Childhood Special Education, 9(4), 78-90.

Safford, P. L. (1989). Integrated teaching in early childhood: Starting in the mainstream. White Plains, NY: Longman.

Sailor, D., \& Guess, W. (1983). Severely handicapped students: An instructional design. Boston: Houghton Mifflin.

Sainato, D. M., \& Carta, J. J. (1992). Classroom influences on the development of social competence in young children with disabilities. In S. Odom, S. McConnell, \& M. McEvoy (Eds.), Social competence of young children with disabilities: Issues and strategies for intervention (pp. 93-109). Baltimore: Brookes.

Spiegel-McGill, P., Bambara, L. M., Shores, R. M., \& Fox, J. J. (1984). The effects of proximity of socially directed behaviors of severely multiply handicapped children. Education and Treatment of Children, 7, 365-378.

Stayton, V. D., \& Miller, P. S. (1993). Combining general and special early childhood education standards in personnel preparation programs: Experiences from two states. Topics in Early Childhood Special Education, 13(3), 372-387. 
Strain, P. S., \& Odom, S. L. (1986). Peer social initiations: Effective intervention for social skills development of exceptional children. Exceptional Children, 52, 543-551.

Tomasello, M., \& Farrar, M. (1986). Joint attention and early language. Child Development, 57, 1454-1463.

Vincent, L. J., \& Beckett, J. A. (1993). Family participation. In DEC Task Force on Recommended Practices, DEC recommended practices: Indicators of quality in programs for infants and young children with special needs and their families (pp. 19-29). Reston, VA: Council for Exceptional Children.

Voeltz, L. M., \& Evans, I. M. (1983). Educational validity. Journal of the Association for Persons With Severe Handicaps, 8(1), 3-15.

Walsh, D. (1991). Extending the discourse on developmental appropriateness. A developmental perspective. Early Education and Development, 2(2), 109-119.

Weiner, E. A., \& Weiner, B. J. (1974). Differentiation of retarded and normal children through toy-play analysis. Multivariate Behavioral Research, 9, 245-257.

Wolery, M., \& Dyk, L. (1984). Arena assessment: Description and preliminary social validity data. Journal of the Association for the Severely Handicapped, 3, 231-235.

Wolery, M., \& Fleming, L. A. (1993). Implementing individualized curricula in integrated settings. In C. A. Peck, S. L. Odom, \&
D. D. Bricker (Eds.), Integrating young children with disabilities into community programs: Ecological perspectives on research and implementation (pp. 109-132). Baltimore: Brookes.

Wolery, M., Strain, P. S., \& Bailey, D. B. (1992). Applying the framework of developmentally appropriate practice to children with special needs. In S. Bredekamp \& T. Rosegrant (Eds.), Reaching potentials: Appropriate curriculum and assessment for 3-8 year olds. Washington, DC: National Association for the Education of Young Children.

Wolock, E. (1990). The relationship of teacher interactive style to the engagement of developmentally delayed preschoolers. Unpublished doctoral dissertation, University of Michigan, Ann Arbor.

Yoder, P. J., \& Davies, B. (1990). Do parent questions and topic continuations elicit replies from developmentally delayed children? A sequential analysis. Journal of Speech and Hearing Research, 23, 563-573.

Yoder, P. J., \& Kaiser, A. P. (1989). Alternative explanations for the relationship between maternal verbal interaction styles and child language development. Journal of Child Language, 16, 141-161.

PERMISSIONS AND COPYRIGHT • All rights are reserved. No part of this publication may be reproduced, photocopied, faxed, stored in a retrieval system, or transmitted, in any form or by any means, electronic, mechanical, recording or otherwise, without the prior written permission of the publisher. • Back issues are available for sale. Reproduction requires permission and payment of fees. It is illegal and a violation of federal copyright law to reproduce this publication without permission. Direct all inquiries to the permissions editor. 


\title{
DOWM SYMOROME: Birth to Adulthood
}

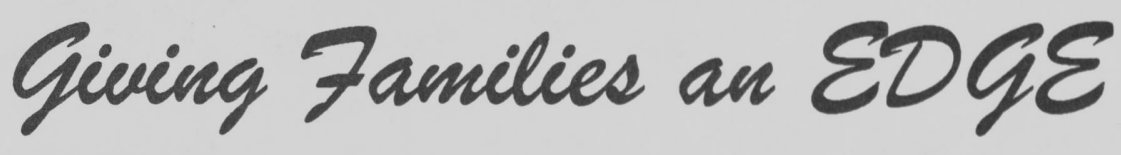

\author{
John E. Rynders \\ J. Margaret Horrobin \\ University of Minnesota \\ Minneapolis Pediatrician
}

Filled with photographs of family activities, Down Syndrome: Birth to Adulthood is an invaluable guide for parents of children with Down syndrome, as well as the professionals who help advance whole-family development. The authors, well-known and respected leaders in the field, use case studies of families from the EDGE Project at the University of Minnesota to examine all the issuesboth large and small -in raising a child with Down syndrome from infancy to adulthood. Research findings from several sources are woven into the pages in a clear, readable fashion, followed with numerous practical suggestions.

All royalties from this book's sale are donated to nonprofit organizations serving people with Down syndrome and their families.

\section{Contents}

A View of Life as a Journey

John Rynders

2 Beginning the Journey

John Rynders

3 Unfolding of the New Baby's Life Within the Family Sophie Thayer

4 Health Promotion During the Early Years Margaret Horrobin

5 Stimulation of the Young Child's Development John Rynders

6 Family Adjustment and Adaptation Brian Abery

7 The School Years: Becoming Literate and Socialized John Rynders
8 One Foot in School, One in a Community Recreation Setting

John Rynders, Stuart Schleien, and Shannon Matson

9 One Hand on the School Door, One on the Door to Work and Independent Living Alan Fletcher

10 Maintaining Health into Adulthood Margaret Horrobin

11 Looking Back, Looking Ahead John Rynders

12 Giving Voice: Young Adults' Perspectives on their Lives

Karon Sherarts and John Rynders

9502/paperback/ISBN 0-89108-236-0/\$29.95

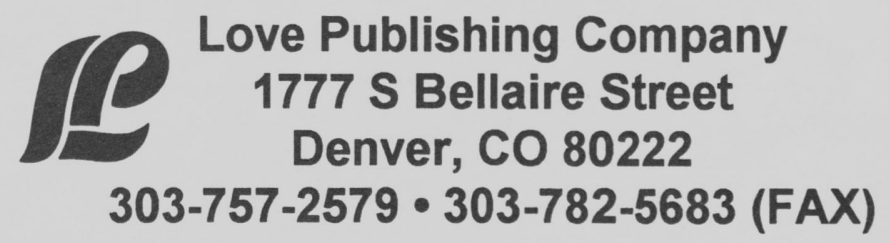




\section{Professional update}

\section{April 5-9, 1995}

CEC Annual Conference

Indiana Convention Center, Indianapolis

Contact: Council for Exceptional Children 1920 Association Drive

Reston, VA 22091

\section{April 10-13, 1995}

Fourth International Special Education Congress Birmingham, England

Contact: John Visser

School of Education

University of Birmingham

Birmingham B15 2TT

England

FAX 021-414-4865

\section{April 18-22, 1995}

American Educational Research Association San Francisco Hilton Hotel

Contact: American Educational Research Association 1230 17th Street, NW

Washington, DC 20036

\section{August 7-10, 1995}

International Association of Special Education International Conference

Brighton, England

Contact: IASE Conference

Continuing Education Services

University of Wisconsin-Whitewater

Whitewater, WI 53190

Telephone: (414) 472-3165 